\title{
A cold-sensitive mutation in 16S rRNA provides evidence for helical switching in ribosome assembly
}

\author{
Carol S. Dammel and Harry F. Noller \\ Sinsheimer Laboratories, University of California at Santa Cruz, Santa Cruz, California 95064 USA
}

A C $\rightarrow$ U substitution at position 23 of $16 \mathrm{~S}$ rRNA confers a dominant, cold-sensitive phenotype. The mutation changes the G11-C23 base pair of the 5' terminal pseudoknot helix to a G-U pair, which is predicted to cause significant weakening of the helix. Ribosomes containing mutant RNA are impaired in assembly and function at low temperature. Cells expressing the $\mathrm{C} 23 \mathrm{U}$ mutation have decreased polysome levels and accumulate free $30 \mathrm{~S}$ and $50 \mathrm{~S}$ subunits and particles that resemble those previously observed in cold-sensitive alleles of ribosomal protein $S 5$ and in in vitro reconstitution of $30 \mathrm{~S}$ subunits carried out at low temperature. Three second-site suppressor mutations suggest that cold sensitivity is caused by competition between the $5^{\prime}$ helix and an alternative helix formed by base-pairing of the upstream precursor sequence with one strand of the mature helix. Cold sensitivity appears to be relieved by destabilization of the competing precursor helix relative to the mature helix.

[Key Words: Cold sensitivity; ribosome assembly; 16S rRNA]

Received September 18, 1992; revised version accepted February 11, 1993.

Ribosome assembly and function are complex dynamic processes and are likely to involve a number of conformational rearrangements, both in the structure of rRNA and in its interactions with ribosomal proteins. One approach to dissection of complex macromolecular processes is the use of conditional mutants (Epstein et al. 1963). We reasoned that dynamic processes involving changes in rRNA structure would depend on the balance between the free energies of different equilibrium states and that mutations leading to alterations in these states might be manifested as temperature-sensitive phenotypes. In previous studies it was found that recessive, temperature-sensitive mutations in 16S rRNA are generally characterized by structural defects, such as mispaired bases in helical stems (Triman et al. 1989). We therefore sought to isolate dominant, conditional $\mathrm{mu}$ tants, with the expectation that such mutants would be more likely to have defects in specific functional processes.

Here, we describe the isolation and properties of a point mutation in rRNA that confers cold sensitivity. This mutant contains a $\mathrm{C} \rightarrow \mathrm{U}$ transition at position 23 of $16 \mathrm{~S}$ rRNA, resulting in the conversion of a G-C basepair in the $5^{\prime}$ terminal helix to a G-U pair. It was unexpected that an apparent weakening of structure should lead to cold sensitivity rather than to temperature sensitivity as seen previously. The properties of several intragenic suppressors of the cold-sensitive mutant lead us to the conclusion that cold sensitivity is caused by a competing helix formed by base-pairing of the upstream precursor sequence with one strand of the mature helix. We describe a kinetic trap model, which rationalizes the behavior of the cold-sensitive mutant and its suppressors. This model may have a bearing on certain longstanding problems in ribosome assembly, including the basis of cold-sensitive mutations in ribosomal protein S5 (Guthrie et al. 1969a; Nashimoto and Nomura 1970; Feunteun et al. 1974/ and the cold-sensitive step of in vitro ribosome assembly known as the RI-RI ${ }^{*}$ transition (Traub and Nomura 1969; Nomura and Held 1974; Dodd et al. 1991).

\section{Results}

\section{Detection of mutants}

Random mutations were introduced by in vitro hydroxylamine mutagenesis of the plasmid pSTL102 coding for a single copy of the rrnB rRNA operon containing a selectable marker for 16S rRNA. A restriction fragment, containing the 16S rRNA gene and its upstream region, was isolated from mutagenized DNA and subcloned into unmutagenized pSTL102 (wild-type) vector to exclude possible mutations elsewhere in the plasmid. Cells transformed with this construct were tested for their ability to grow conditionally on ampicillin (Amp)-containing media at high $\left(42^{\circ} \mathrm{C}\right)$ and low $\left(26^{\circ} \mathrm{C}\right)$ temperatures. Ribosomes derived from plasmid-encoded $16 \mathrm{~S}$ rRNA are spectinomycin resistant $\left(\mathrm{Spc}^{\mathrm{r}}\right)$, as a result of a $\mathrm{C} \rightarrow \mathrm{U}$ mutation at position 1192; therefore, phenotypes 
that are expressed only in the presence of spectinomycin ( $\mathrm{Spc}_{60}$ medium) are interpreted as recessive mutations in 16 S rRNA. Conversely, phenotypes that are expressed in the absence of spectinomycin, on Amp-containing media (which selects for maintenance of the plasmid), are taken to be dominant, because both chromosomally and plasmid-encoded 16S rRNAs are expressed under those conditions.

\section{$A C \rightarrow U$ mutation at position 23 confers dominant cold sensitivity}

From $\sim 6000$ colonies screened, four dominant cold-sensitive candidates were obtained; no temperature-sensitive candidates were found. Plasmid DNA was prepared from the candidates and shown to confer the cold-sensitive phenotype to newly transformed cells. The mutation responsible for the cold-sensitive phenotypes was localized by restriction fragment exchange and identified by DNA sequence analysis as described by Triman et al. (1989).

Restriction fragment exchanges, between the four mutant plasmids and pSTL102 (wild type), localized the site of the cold-sensitive mutation to the $5^{\prime}$ end of the $16 \mathrm{~S}$ rRNA gene and its upstream region, between nucleotide positions -358 and 80 (BstBI-HindIII fragment; Table 1). DNA sequence analysis revealed a single $\mathrm{C} \rightarrow \mathrm{U}$ nucleotide alteration at position 23 in each of the four in-

Table 1. Identification of dominant cold-sensitive mutation and second-site suppressor mutations

\begin{tabular}{|c|c|c|c|}
\hline $\begin{array}{l}\text { Plasmid } \\
\text { name }\end{array}$ & Fragment & $\begin{array}{l}\text { Nucleotide } \\
\text { alteration }(s)^{\mathbf{a}}\end{array}$ & $\begin{array}{l}\text { Independent } \\
\text { isolates }\end{array}$ \\
\hline pU23 & BstBI-HindIII & $\mathrm{C} 23 \rightarrow \mathrm{U}$ & 4 \\
\hline pA11U23 & $B s t \mathrm{BI}-B c I I$ & $\begin{array}{l}\mathrm{G} 11 \rightarrow \mathrm{A} \\
\mathrm{C} 23 \rightarrow \mathrm{U}\end{array}$ & 3 \\
\hline pA15U23 & BamHI-BclI & $\begin{array}{l}\mathrm{G} 15 \rightarrow \mathrm{A}, \\
\mathrm{C} 23 \rightarrow \mathrm{U}\end{array}$ & 3 \\
\hline $\mathrm{pU}-5 \mathrm{U} 23$ & BamHI-BclI & $\begin{aligned} \mathrm{C}-5 & \rightarrow \mathrm{U} \\
\mathrm{C} 23 & \rightarrow \mathrm{U}\end{aligned}$ & 5 \\
\hline $\mathrm{pU}-55 \mathrm{U} 23$ & BamHI-BclI & $\begin{aligned} \mathrm{C}-55 & \rightarrow \mathrm{U} \\
\mathrm{C} 23 & \rightarrow \mathrm{U}\end{aligned}$ & 2 \\
\hline $\mathrm{pA}-114 \mathrm{U} 23$ & BamHI-BclI & $\begin{array}{c}\mathrm{G}-114 \rightarrow \mathrm{A} \\
\mathrm{C} 23 \rightarrow \mathrm{U}\end{array}$ & 3 \\
\hline $\mathrm{pA}+8 \mathrm{U} 23$ & BstEII-XbaI & $\begin{aligned} \mathrm{G}+8 & \rightarrow \mathrm{A} \\
\mathrm{C} 23 & \rightarrow \mathrm{U}\end{aligned}$ & 1 \\
\hline $\mathrm{pA}+13 \mathrm{U} 23$ & BstEII $-X b a \mathrm{I}$ & $\begin{array}{c}\mathrm{G}+13 \rightarrow \mathrm{A}, \\
\mathrm{C} 23 \rightarrow \mathrm{U}\end{array}$ & 1 \\
\hline $\mathrm{pA}+23 \mathrm{U} 23$ & BstEII-XbaI & $\begin{array}{c}\mathrm{G}+23 \rightarrow \mathrm{A}, \\
\mathrm{C} 23 \rightarrow \mathrm{U}\end{array}$ & 1 \\
\hline $\mathrm{pA}+25 \mathrm{U} 23$ & BstEII-XbaI & $\begin{array}{c}\mathrm{G}+25 \rightarrow \mathrm{A}, \\
\mathrm{C} 23 \rightarrow \mathrm{U}\end{array}$ & 1 \\
\hline
\end{tabular}

${ }^{a}$ All nucleotide positions discussed in this paper are identified by their position relative to the first nucleotide of $16 \mathrm{~S}$ rRNA. plasmid names reflect which nucleotide alterations they contain. Nucleotide positions upstream from the 5 mature end of $16 \mathrm{~S}$ rRNA are numbered as negative, with -1 being the first nucleotide $5^{\prime}$ of the start of 16S rRNA. Nucleotide positions downstream $\left\{3^{\prime} \mid\right.$ of $16 \mathrm{~S}$ rRNA are numbered as positive, with +1 being the first nucleotide $3^{\prime}$ of the $3^{\prime}$ end of $16 S$ rRNA.

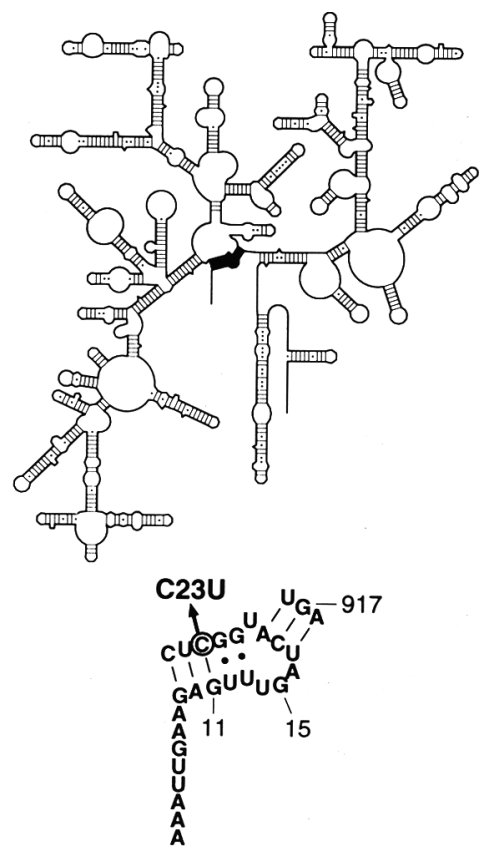

Figure 1. Position of the cold-sensitive C23U mutation in $16 \mathrm{~S}$ rRNA; also indicated are the sites of suppressor mutations at positions 11 and 15 .

dependently isolated mutants. The position of this single-base change in 16S rRNA is shown in Figure 1.

Cells containing U23 mutant plasmid (pU23) grew nearly as well as pSTL102-containing cells on Amp Amo $_{10}$ plates at $42^{\circ} \mathrm{C}$, the most permissive temperature. In contrast, pU23-containing cells failed to grow or grew only very weakly after $48 \mathrm{hr}$ on $\mathrm{Amp}_{100}$ plates at $26^{\circ} \mathrm{C}$ (nonpermissive), relative to wild type (Fig. 2; Table 2).

Permissive growth on $\mathrm{Amp}_{100}$ at $42^{\circ} \mathrm{C}$ could either be the result of a recessive defect in $16 \mathrm{~S}$ rRNA or reversal of the loss of function observed at $26^{\circ} \mathrm{C}$ at the higher temperature. To distinguish between these possibilities, pU23-containing cells were tested directly for expression of plasmid-encoded $16 \mathrm{~S}$ rRNA at $26^{\circ} \mathrm{C}$ and $42^{\circ} \mathrm{C}$ by plating on spectinomycin. Mutant-containing cells grew equally well on $\mathrm{Spc}_{60}$ and $\mathrm{Amp}_{100}$ plates at $42^{\circ} \mathrm{C}$, demonstrating that the ability of these cells to grow on $A m p_{100}$ plates at $42^{\circ} \mathrm{C}$ is attributable to restoration of function rather than to inactivation of mutant ribosomes.

Cells containing U23 were grown in $\mathrm{Amp}_{100}$ broth at $26^{\circ} \mathrm{C}, 32^{\circ} \mathrm{C}, 37^{\circ} \mathrm{C}$, and $42^{\circ} \mathrm{C}$, and their growth curves were compared with those from cells containing the reference pSTL102 plasmid (Fig. 3). The growth rate of pU23-containing cells is significantly slower than that of pSTL102-containing cells at all temperatures. Consistent with the plate phenotype, this growth rate difference diminishes dramatically with increasing temperature, approaching that of wild type at $42^{\circ} \mathrm{C}$.

To examine the rate of onset and the reversibility of the cold-sensitive phenotype, we carried out temperature-shift experiments (Fig. 4). Amp 100 $_{10}$ cultures growing 


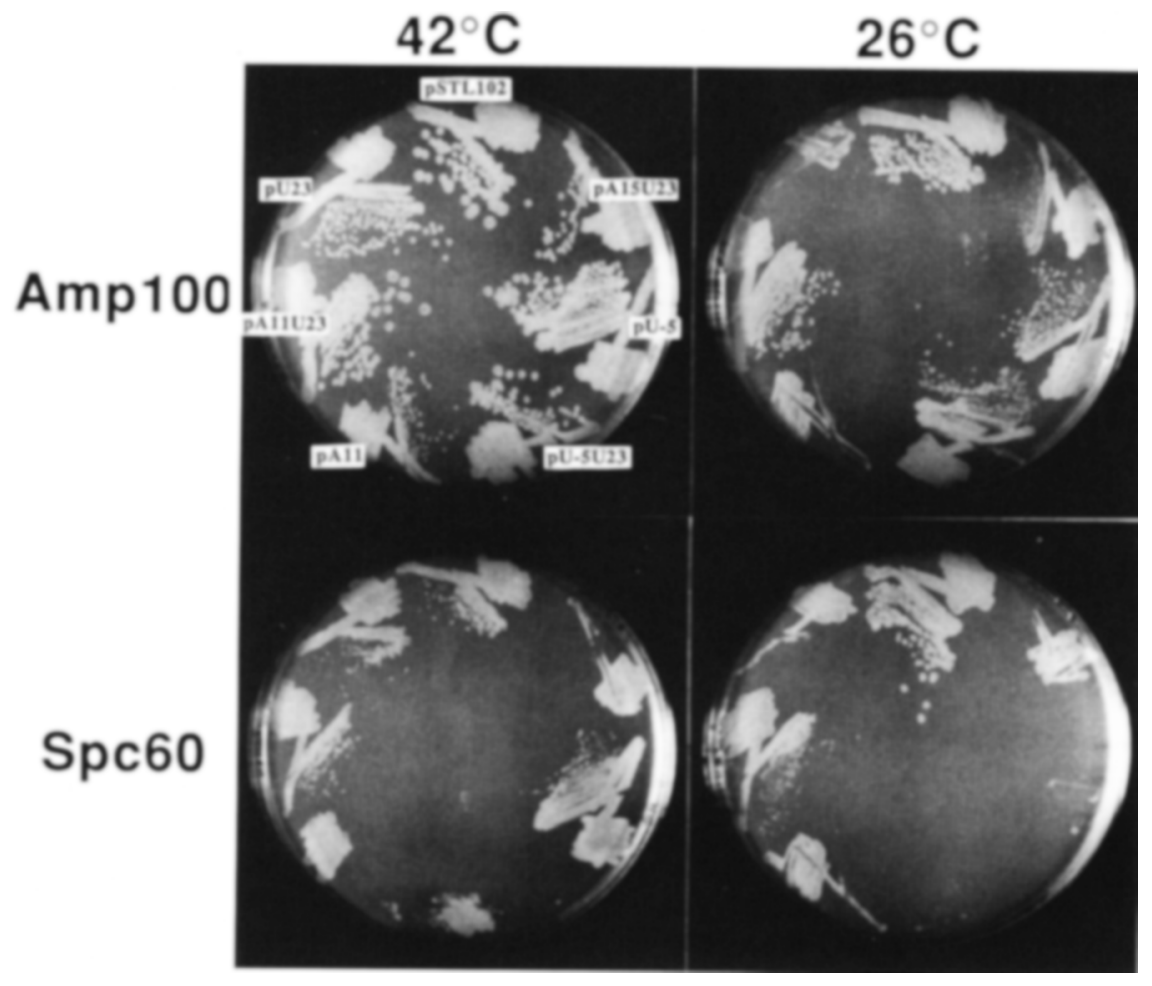

Figure 2. Cold-sensitive growth of pU23containing cells compared with cells containing the parent plasmid pSTL102, the revertants pAllU23, pAl5U23, and $\mathrm{pU}-5 \mathrm{U} 23$, and the second-site-segregated suppressor mutations $\mathrm{pAll}$ and $\mathrm{pU}-5$, on ampicillin- and spectinomycin-containing media. at $42^{\circ} \mathrm{C}$ were shifted to $26^{\circ} \mathrm{C}$, for $\sim 1.5$ doublings, followed by a shift back to $42^{\circ} \mathrm{C}$. Shifting to $26^{\circ} \mathrm{C}$ caused immediate cold sensitivity, and upon shift back to $42^{\circ} \mathrm{C}$ the mutant cells immediately resumed their normal growth rate. These results are most consistent with the interpretation that the cold-sensitive phenotype is the result of disruption of ribosomal function, and/or a rapidly reversible defect in ribosome assembly.
U23 confers cold sensitivity independently of the U1192 Spc mutation

As some of the subunit assembly-defective $\mathrm{S} 5$ mutations described earlier (Nashimoto et al. 1971) conferred both cold sensitivity and $\mathrm{Spc}^{\mathrm{r}}$ phenotypes, we tested whether the selective $\mathrm{Spc}^{\mathrm{r}}$ marker $(\mathrm{Cl} 192 \mathrm{U})$ in pSTL102 has an effect on the $\mathrm{C} 23 \mathrm{U}$ cold-sensitive mutation. After segre-

Table 2. Growth properties of mutants on selective plates

\begin{tabular}{|c|c|c|c|c|c|}
\hline \multirow[b]{2}{*}{ Plasmid name } & \multicolumn{2}{|c|}{$42^{\circ} \mathrm{C}^{\mathrm{a}}$} & \multicolumn{2}{|c|}{$26^{\circ} \mathrm{C}^{\mathrm{a}}$} & \multirow[b]{2}{*}{ Revertant class } \\
\hline & $A m p_{100}$ & $\mathrm{Spc}_{60}$ & $A m p_{100}$ & $\mathrm{Spc}_{60}$ & \\
\hline pSTL102 & ++++ & ++++ & ++++ & $++t+$ & \\
\hline pU23 & ++ & ++++ & \pm & \pm & \\
\hline pA11U23 & +++ & ++++ & +++ & ++ & 1 \\
\hline pAll & + & \pm & + & \pm & \\
\hline pA15U23 & +++ & + & ++ & \pm & $2 / 3$ \\
\hline $\mathrm{pU}-5 \mathrm{U} 23$ & ++++ & \pm & +++ & - & 2 \\
\hline $\mathrm{pU}-5$ & +++ & +++ & +++ & - & \\
\hline $\mathrm{pU}-55 \mathrm{U} 23$ & ++++ & \pm & +++ & - & 2 \\
\hline $\mathrm{pU}-55$ & +++ & - & +++ & - & \\
\hline $\mathrm{pA}-114 \mathrm{U} 23$ & ++ & - & +++ & - & 2 \\
\hline $\mathrm{pA}-114$ & +++ & - & $+t+$ & - & \\
\hline $\mathrm{pA}+8 \mathrm{U} 23$ & ++++ & - & + & - & 3 \\
\hline $\mathrm{pA}+8$ & $++t+$ & \pm & ++++ & - & \\
\hline $\mathrm{pA}+13 \mathrm{U} 23$ & +++ & - & +++ & - & 2 \\
\hline $\mathrm{pA}+23 \mathrm{U} 23$ & +++ & - & +++ & - & 2 \\
\hline $\mathrm{pA}+25 \mathrm{U} 23$ & +++ & - & $++t$ & - & 2 \\
\hline
\end{tabular}

a +++$)$ Full-sized colonies; $(+++,++,+)$ isolated colonies that are smaller than full size, where +++ is the largest; $( \pm)$ weak growth (no isolated colonies); (-) no detectable growth. 

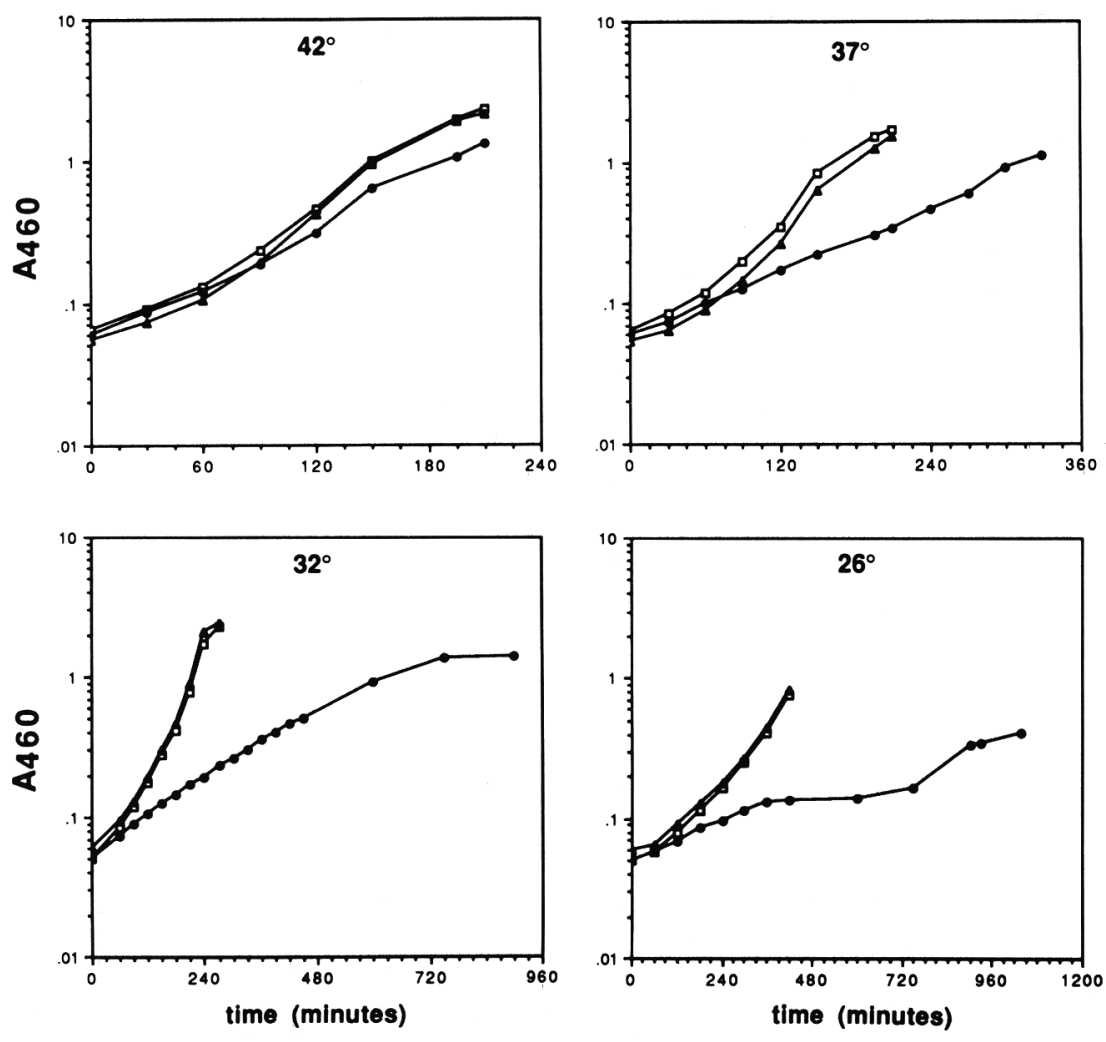

Figure 3. Growth of cells transformed with pSTL102 (wild-type, $\square$ ), pU23 (cold-sensitive, I, and pAl1U23 (revertant, $\Delta$ ) in ampicillincontaining cultures at $42^{\circ} \mathrm{C}, 37^{\circ} \mathrm{C}, 32^{\circ} \mathrm{C}$, and $26^{\circ} \mathrm{C}$ (inoculated from $37^{\circ} \mathrm{C}$ overnight cultures at $t=0)$. gation of U23 from U1192 by restriction fragment exchange, the dominant cold-sensitive phenotype of the U23 mutation was found to persist in the absence of U1192 (data not shown), indicating that the two mutations do not interact to give cold sensitivity.

\section{Suppressors of cold sensitivity}

To explore further the basis of the U23 mutation, we sought second-site RNA mutations that could suppress the cold-sensitive phenotype. Plasmid DNA containing the $\mathrm{C} 23 \mathrm{U}$ change was mutagenized with hydroxylamine, and transformants were screened for suppression of the cold-sensitive phenotype. Twenty-one independent revertants were isolated, and second-site suppressors were localized by restriction fragment exchange (Table 1). DNA sequence analysis showed that the suppressors comprise nine different mutations located within the 16S rRNA gene and its upstream or downstream flanking sequences (Table 1). For those revertants localized to the BamHI-BclI fragment (U23A15, U23U - 5, U23A-114), the entire fragment was not sequenced; however, nucleotides -330 to 14 (BclI $\rangle$, including the entire $\mathrm{rnB}$ promoter region, have been sequenced, revealing no other changes. The phenotypes of cells containing revertant plasmids are summarized in Table 2.

Two second-site suppressors to the cold-sensitive C23U change were located within the pseudoknot helix. One of these, G11A, restores potential Watson-Crick base-pairing to the weakened, pseudoknot helix
(G11U23 to A11U23) and restores growth to virtually wild-type levels. These results provide strong evidence that Watson-Crick base-pairing at this position is critical for proper functioning of the ribosome. Because weakening of this base-pair by the C23U change confers cold-sensitive growth, we tested the effect of disruption of this base-pair by the second-site suppressor mutation G11A, independent of the C23U change. The growth rate of the single mutant GllA, which creates an A-C mismatch, was very poor at all temperatures on both $\mathrm{Amp}_{100}$ and $\mathrm{Spc}_{60}$ plates (Table 2; Fig. 2), providing additional evidence for the functional importance of the G11-C23 base-pair. However, because the G11A change does not result in cold sensitivity and the C23U change does, it is apparent that cold sensitivity is not simply attributable to disruption of the $5^{\prime}$ helix. The G15A mutation, located within the loop region of the pseudoknot (Fig. 1) causes moderate suppression of cold sensitivity (Table 2; Fig. 2).

In a previous study, recessive temperature-sensitive mutants were localized to positions $-13,-30$, and -59 in the upstream precursor region (Mori et al. 1989). Because three of the suppressors isolated in the present work $(\mathrm{C}-5 \mathrm{U}, \mathrm{C}-55 \mathrm{U}$, and $\mathrm{G}-114 \mathrm{~A})$ are $\mathrm{Spc}^{\mathrm{s}}$ under conditions where cold sensitivity is suppressed, the resulting double mutants $\{\mathrm{U}-5 \mathrm{U} 23, \mathrm{U}-55 \mathrm{U} 23$, and $U-114 \mathrm{U} 23$ ) behave like recessive lethals. We therefore asked whether the second-site suppressor mutations, when segregated from the original cold-sensitive $\mathrm{C} 23 \mathrm{U}$ mutation, confer recessive $\left(\mathrm{Spc}_{\mathrm{s}}\right.$ or $\left.\mathrm{Spc}_{\mathrm{ts}}\right)$ pheno- 

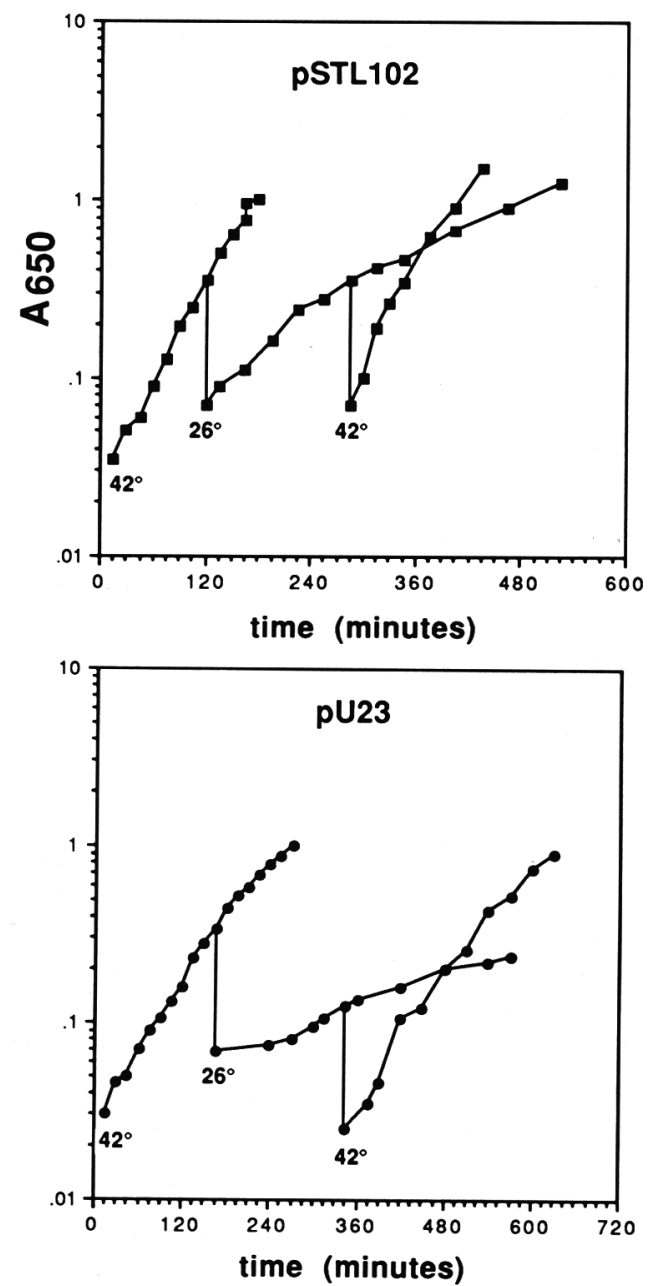

Figure 4. Temperature-shift experiments comparing pSTL102 and pU23. Cultures growing in $\mathrm{Amp}_{100}$ broth at the permissive temperature of $42^{\circ} \mathrm{C}$ were diluted $1: 5$ into fresh $A_{100}$ broth and shifted to $26^{\circ} \mathrm{C}$, and again diluted $1: 5$ into fresh $\mathrm{Amp}_{100}$ broth and shifted to $42^{\circ} \mathrm{C}$, as shown.

types or whether the presence of both mutations is required.

The second-site suppressors were segregated from $\mathrm{C} 23 \mathrm{U}$ by restriction fragment exchange. The single mutants C-55U and G-114A exhibited wild-type growth on $\mathrm{Amp}_{100}$ plates but failed to grow on $\mathrm{Spc}_{60}$ plates at either temperature. The recessive phenotypes of the single mutants $\mathrm{U}-55$ and $\mathrm{A}-114$ are thus identical to those of their respective double mutants. These suppressors therefore appear to act independently of the original C23U mutation.

In contrast, the single mutation $\mathrm{C}-5 \mathrm{U}$ confers a slight reduction of colony size on $\mathrm{Amp}_{100}$ plates at either temperature and cold sensitivity on $\mathrm{Spc}_{60}$ plates (Fig. 2). The cold sensitive Spc phenotype of the $\mathrm{C}-5 \mathrm{U}$ single mutant is distinct from that of the $\mathrm{U}-5 \mathrm{U} 23$ double mutant, which is $\mathrm{Spc}_{\mathrm{s}}$ at either temperature. This result is interesting, in that the phenotype of the $\mathrm{U}-5 \mathrm{U} 23$ double mutant differs from that of either the $\mathrm{C} 23 \mathrm{U}$ or $\mathrm{C}-5 \mathrm{U}$ single mutants. This suggests that the $\mathrm{C}-5 \mathrm{U}$ suppressor interacts in some way with the original $\mathrm{C} 23 \mathrm{U}$ mutation. The $A+8 \mathrm{U} 23$ double mutant, in which the suppressor mutation is located in the spacer region downstream from the 16S rRNA gene, shows wild-type growth on $\mathrm{Amp}_{100}$ at $42^{\circ} \mathrm{C}$, but grows only slightly better than the cold-sensitive $\mathrm{U} 23$ mutant at $26^{\circ} \mathrm{C}$. In contrast, the corresponding single mutant $\mathrm{A}+8$ exhibits wild-type growth on $A m p_{100}$ at either temperature. Both the $\mathrm{A}+8 \mathrm{U} 23$ double mutant and the $\mathrm{A}+8$ single mutant fail to grow on $\mathrm{Spc}_{60}$ at either temperature. Again, like the $\mathrm{C}-5 \mathrm{U}$ result, the single suppressor mutant differs from that of the double mutant, suggesting that it may interact directly with the original C23U mutation.

\section{Cellular distribution of mutant $16 S$ rRNA}

To understand better the basis of the observed cold sensitive growth defect, we analyzed the cellular distribution of the mutant $16 \mathrm{~S}$ rRNA, in comparison with that of the chromosomally encoded wild-type RNA. Ribosomes, subunits, and polysomes prepared from cells containing pU23 or pSTL102, grown at the permissive or nonpermissive temperature, were separated by sucrose gradient centrifugation. Cells carrying the mutant $\mathrm{pU} 23$ showed a decreased amount of polysomes and an increase in $30 \mathrm{~S}$ and $50 \mathrm{~S}$ subunits at both temperatures, but the effects were most pronounced at $26^{\circ} \mathrm{C}$ (data not shown). These effects bear a resemblance to those observed for coldsensitive protein mutants in earlier studies /Guthrie et al. 1969a,b; Nashimoto and Nomura 1970; Nashimoto et al. 1971; Feunteun et al. 1974). We utilized the U1192 marker to monitor the presence of plasmid-derived $16 \mathrm{~S}$ rRNA in pSTL102- and pU23-containing cells, using the method of Sigmund et al. (1988). No significant differences in the proportion of plasmid-derived 16S rRNA were found in the $70 \mathrm{~S}$ peak from cells containing the mutant pU23 at $26^{\circ} \mathrm{C}$, relative to cells containing the wild-type pSTL102 plasmid (Table 3). The increased levels of aberrant particles and free $30 \mathrm{~S}$ subunits in mutantcontaining cells, however, are completely accounted for by an increase in mutant RNA-containing particles, which were found to be composed almost exclusively of U23-containing rRNA (Table 3).

Ribosomes prepared from cells containing pSTL102, pU23, pA11U23, pA15U23, pU $-5 U 23$, and pA + 8 U23 grown at $37^{\circ} \mathrm{C}$ were analyzed by sucrose gradient sedi-

Table 3. Relative proportion of plasmid-encoded 16S rRNA from sucrose gradient peak fractions

\begin{tabular}{lcc}
\hline & $70 S$ & $30 S$ \\
\hline pSTL102 & 85 & 86 \\
pU23 & 77 & 92
\end{tabular}

Numbers given are [(plasmid RNA)/(plasmid RNA + chromosomal RNA)] $\times 100$. Relative amounts of plasmid-derived vs. chromosomally derived $16 \mathrm{~S}$ rRNA were estimated by primer extension of RNA extracted from ribosomes, as described in Materials and methods. 
mentation (Fig. 5). The gradient profile obtained from cells carrying pU23 was similar to that described above. Also evident are a broadening of the $30 \mathrm{~S}$ and $50 \mathrm{~S}$ subunit peaks and the appearance of slower-moving shoulders on both the $30 \mathrm{~S}$ and $50 \mathrm{~S}$ peaks. The profile of the A11U23 mutant was indistinguishable from that of cells carrying pSTL102 (Fig. 5), consistent with its virtually wild-type behavior. Profiles obtained from cells carrying pA15U23, $\mathrm{pU}-5 \mathrm{U} 23$, and $\mathrm{pA}+8 \mathrm{U} 23$ showed the same kinds of anomalies seen for $\mathrm{pU} 23$ but were less severe; most pronounced was pA15U23, followed by pA $+8 \mathrm{U} 23$, followed by $\mathrm{pU}-5 \mathrm{U} 23$, which closely resembled pSTL102. The degrees of severity of the different sedimentation profiles $\quad$ (pU23 $\rightarrow$ pA15U23 $\rightarrow$ pA $+8 \mathrm{U} 23 \rightarrow$ pU $-5 \mathrm{U} 23 \rightarrow$

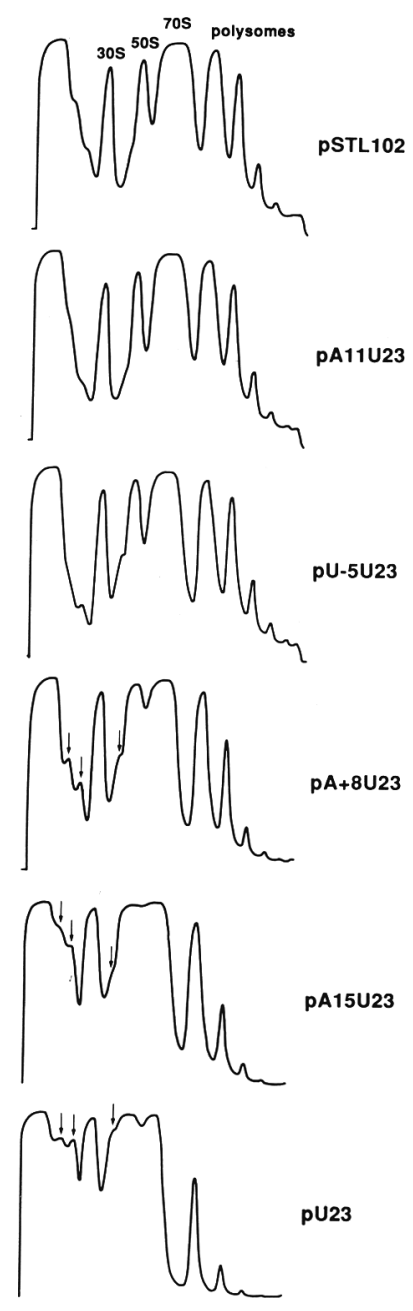

Figure 5. Polysome profiles from cells containing wild-type pSTL102 or mutant pU23, pA11U23, pA15U23, pU-5U23, and $\mathrm{pA}+8 \mathrm{U} 23$ plasmids. Freshly inoculated $100-\mathrm{ml}$ cultures were grown at $37^{\circ} \mathrm{C}$ to $A_{650}=0.5$. Cells were chilled rapidly, and polysomes were prepared (Powers and Noller 1990). Lysates were layered onto $10-\mathrm{ml} 10-40 \%$ sucrose gradients, made in buffer containing $20 \mathrm{~mm}$ Tris- $\mathrm{HCl}(\mathrm{pH} 7.8), 10 \mathrm{mM} \mathrm{MgCl}_{2}, 100$ $\mathrm{mM} \mathrm{NH} \mathrm{NCl}_{4} 6 \mathrm{mM} \beta$-mercaptoethanol, and centrifuged in an SW-41 rotor for $2.5 \mathrm{hr}$ at $35,000 \mathrm{rpm}$ and $4^{\circ} \mathrm{C}$. Absorbance at 254 $\mathrm{nm}$ was analyzed continuously using an ISCO gradient fractionator, and $0.750-\mathrm{ml}$ fractions were collected.
pA11U23 = pSTL102 $\}$ correlate inversely with the ability of the respective second-site mutations to suppress cold sensitivity (Table 2).

No significant differences in the proportion of plasmid-derived versus chromosomally derived $16 \mathrm{~S}$ rRNA were observed in polysome peaks from cells containing pSTL102, pU23, pA11U23, pA15U23, pU-5U23, or $\mathrm{pA}+8 \mathrm{U} 23$ at $37^{\circ} \mathrm{C}$, indicating that despite the $\mathrm{Spc}^{\mathrm{s}}$ phenotypes of cells containing pA15U23, pU-5U23, or $\mathrm{pA}+8 \mathrm{U} 23$, ribosomes containing these mutant $16 \mathrm{~S}$ rRNAs are able to assemble into functional polysomes (data not shown). Additionally, as shown above, the fact that the pU-5U23 gradient closely resembles that of wild type shows that the U -5 mutation does not simply result in inactive $\mathrm{U} 23$ ribosomes but actually rescues whatever defects are responsible for the sedimentation anomalies.

\section{Structure probing of mutant ribosomes}

The higher order structure of 16S rRNA in pU23-containing ribosomes was examined using kethoxal as a probe for the accessibility of N1 and/or N2 positions of guanine residues. Total ribosomal particles, obtained by high-speed centrifugation of extracts of cells carrying pSTL102, pU23, pU -5 , or $\mathrm{pU}-5 \mathrm{U} 23$ grown at $37^{\circ} \mathrm{C}$, were modified with kethoxal at $26^{\circ} \mathrm{C}$. rRNA was than extracted, and primer extension was performed to identify modified guanines (Stern et al. 1988a). It should be noted that this technique monitors the reactivities of both plasmid- and chromosomally derived rRNAs. The $\mathrm{U} 23$ mutation confers increased reactivity of many $\mathrm{G}$ residues throughout $16 \mathrm{~S}$ rRNA. Examples of increased reactivities seen in the $5^{\prime}$ terminal helix region for $\mathrm{U} 23$ containing particles are shown in Figure 6 (lane 7). These enhanced reactivities are indicative of abnormally assembled $30 \mathrm{~S}$ subunits and most likely reflect incomplete assembly. In contrast, particles from the $\mathrm{U}-5 \mathrm{U} 23$ suppressor strain (lane 6) show a pattern of kethoxal reactivity that is indistinguishable from that of wild type (lane 8). Thus, both the sedimentation profiles and kethoxal reactivity patterns indicate that the C23U mutation results in the defective assembly of small subunits. By both criteria, the upstream $\mathrm{C}-5 \mathrm{U}$ suppressor reverses this assembly defect, in parallel with its ability to suppress the cold sensitive phenotype.

The higher order structures of the aberrant particles, the free $30 S$ peak, and the $70 S$ ribosome peak obtained from U23- and pSTL102-containing cells grown at $26^{\circ} \mathrm{C}$ (Table 3) were examined, again using kethoxal as a probe. Enhanced reactivities similar to those seen in Figure 6 were found almost exclusively in the aberrant and free $30 \mathrm{~S}$ peaks of U23-containing cells (data not shown).

Primer extension analysis of $5^{\prime}$ processing of $16 S$ $r R N A$

Because suppressors of the cold-sensitive C23U mutation were found upstream from the $5^{\prime}$ end of mature $16 \mathrm{~S}$ rRNA, we asked whether cold sensitivity could be 
C $\quad$\begin{tabular}{lllllllll}
\hline & 1 & 2 & 3 & 4 & 5 & 6 & 7 & 8
\end{tabular}

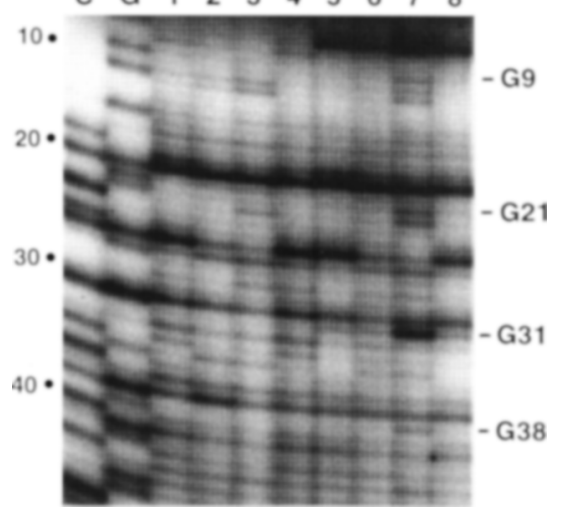

Figure 6. Chemical probing of the $5^{\prime}$-terminal region of $16 \mathrm{~S}$ rRNA using kethoxal (Stern et al. 1988b). Modified bases were scanned using primer extension with the 162 primer. Total ribosomal particles isolated from cells containing $\mathrm{pU}-5$, pU-5U23, pU23, or pSTL102 were probed with kethoxal (KE): (Lane 1) pU-5, no KE; (lane 2) pU - 5U23, no KE; (lane 3) pU23, no $\mathrm{KE}$; (lane 4) pSTL102, no KE; (lane 5), $\mathrm{pU}-5, \mathrm{KE}$; (lane 6) $\mathrm{pU}-5 \mathrm{U} 23, \mathrm{KE}$; (lane 7) pU23, KE (lane 8) pSTL102, KE. (C,G) Dideoxy-sequencing lanes.

caused by defective $5^{\prime}$ processing of $16 \mathrm{~S}$ rRNA. The $5^{\prime}$ ends of 16S rRNA were located by primer extension analysis of total cellular RNA using two primers: one that anneals to nucleotides -18 through -1 jupstream primer), and one that anneals to nucleotides 6-22 of mature 16S rRNA (internal primer) (Fig. 7). These two primers allow us to distinguish between covalently and noncovalently associated upstream RNA sequences.

There are clear indications that the $\mathrm{C} 23 \mathrm{U}$ mutation causes processing anomalies, as seen from the accumulation of incompletely processed $5^{\prime}$ ends (Fig. 7, lane 2). These anomalies, however, are also observed for the A11U23 double mutant (lane 3) and are independent of temperature (data not shown). Furthermore, similar amounts of precursor RNA are found in ribosomes containing either U23 mutant or double-mutant suppressor rRNA, isolated from polysomes derived from cells grown at either the restrictive or permissive temperatures. Thus, defective $5^{\prime}$ processing cannot be the cause of cold sensitivity.

\section{Discussion}

\section{Alternative RNA structures and cold sensitivity}

The mutant described here, in which position $\mathrm{C} 23$ of mature 16S rRNA is changed to $U$, results in a reversibly cold sensitive, dominant phenotype. This mutation replaces the highly conserved G11-C23 base-pair in the 5 '-proximal helix, with a G-U pair (Fig. 1). That an apparent weakening of a structural element should give rise to a cold-sensitive phenotype was unexpected. In a previous study, disruption of Watson-Crick base-pairs was generally found to confer temperature sensitivity (Triman et. al. 1989). Isolation of upstream second-site suppressor mutations suggested the possibility of a com- peting structure involving the precursor RNA. Three effective suppressor mutations, G11A, G15A, and C-5U, are all located within a potential helix, proposed previously by Young and Steitz (1978), that is formed by the pairing of upstream positions -1 through -10 with residues $7-16$ of mature 16 SRNA (Fig. 8). This helix would compete with the 5 '-terminal helix of mature 16S rRNA, because they share several common nucleotides (Fig. 8).

A

B

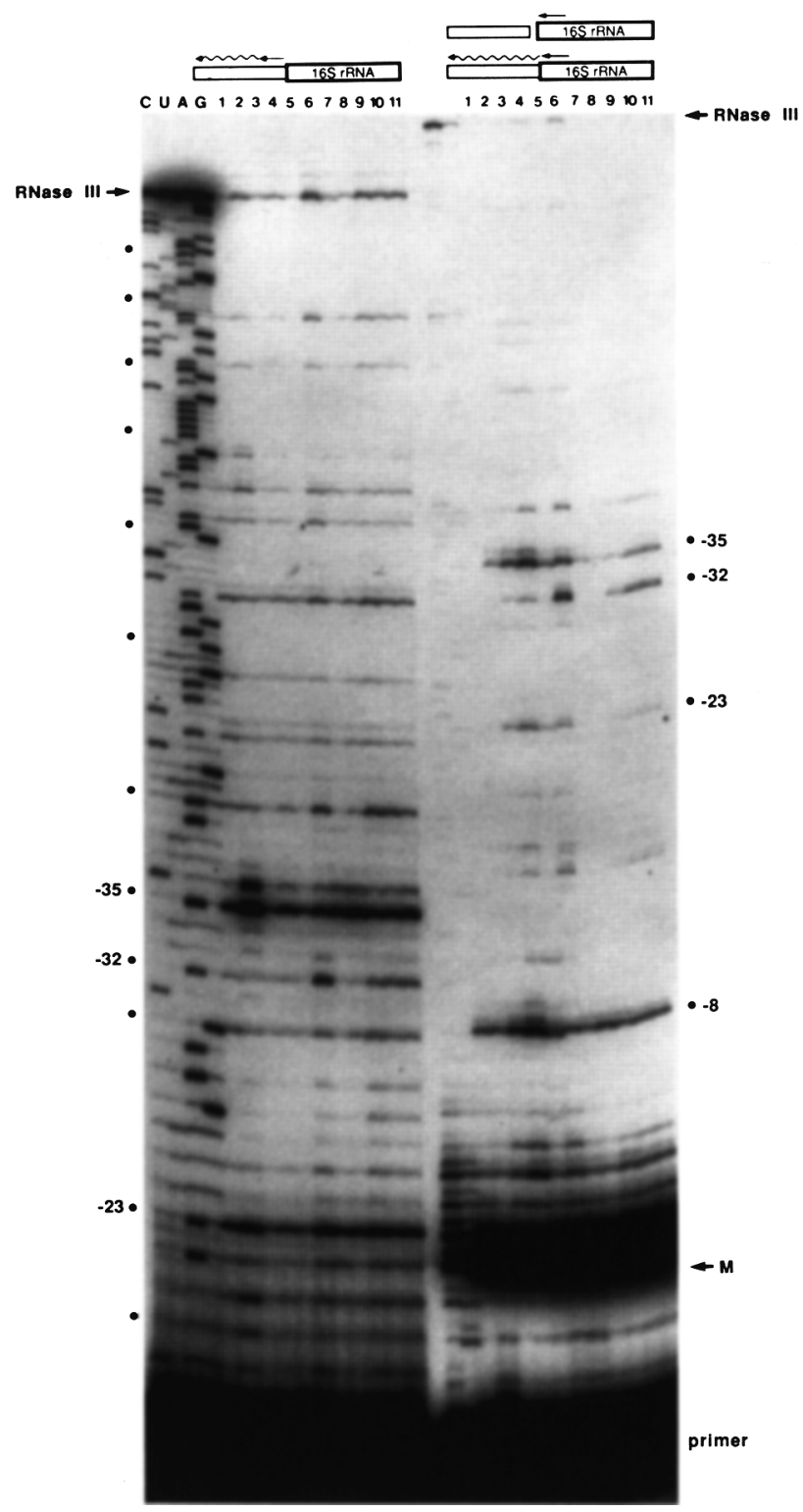

Figure 7. Primer extension analysis of the $5^{\prime}$ end of 165 rRNA with precursor-specific $(A)$ or $16 \mathrm{~S}$ rRNA-specific $(B)$ primer, using total $16 \mathrm{~S}$ rRNA from cells grown in ampicillin at $37^{\circ} \mathrm{C}$. (Lanes 1) pSTL102; (lanes 2) pU23; (lanes 3) pA11U23; (lanes 4) pA15U23; (lanes 5) pU-5U23; (lanes 6) pU-55U23; (lanes 7) pA-114U23; (lanes 8) pA + 8U23; (lanes 9) pA+13U23; (lanes 10) pA + 23U23; and (lanes 11) pA + 25U23. The RNase III cleavage site (Young and Steitz 1978) and the mature 5' end of $16 \mathrm{~S}$ rRNA (M) are indicated. 

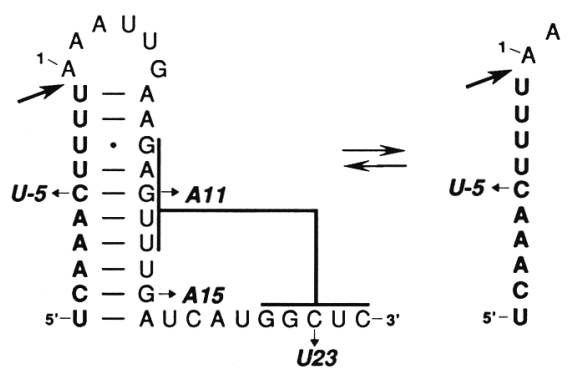

Figure 8. Model depicting two competing RNA secondary structures. (Left) A potential upstream helix (Young and Steitz 1978), formed by the pairing of an upstream precursor sequence with a segment of mature $16 \mathrm{~S}$ rRNA; (right) the phylogenetically established 5' mature helix (Woese et el. 1983), which contains the site of the primary cold-sensitive mutation C23U, and whose hairpin loop is involved in a long-range pseudoknot interaction. Sites of the suppressor mutations C-5U, G11A, and G15A are indicated, as is the $5^{\prime}$ mature end of $16 \mathrm{~S}$ rRNA (arrow).

All three of these suppressor mutations are predicted to destabilize the competing precursor helix relative to the mature helix, because they replace $\mathrm{G}-\mathrm{C}$ base pairs in the precursor helix with a weaker $\mathrm{G}-\mathrm{U}$ pair or A-C mismatches; the mature helix is either somewhat strengthened (in the case of the G11A mutation) or unaffected by the suppressor mutations.

We do not yet fully understand the basis of the cold sensitivity conferred by the C23U mutation. It is clear, however, that all mutations isolated so far that weaken the competing precursor helix effectively relieve cold sensitivity. C23U-containing cells grown at low temperature accumulate large amounts of free $30 \mathrm{~S}$ subunits and slower sedimenting particles (Fig. 5), which include incompletely assembled $30 \mathrm{~S}$ subunits whose chemical probing pattern (Fig. 6) bears resemblance to that of incompletely assembled reconstitution intermediate (RI) particles formed in vitro at low temperature /Traub and Nomura 1969; T. Powers, unpubl.). The anomalous probing pattern is reversed by the $U-5$ suppressor (Fig. 6, lane 6), indicating that this suppressor acts directly to correct the assembly defect, rather than creating a recessive defect. Although the A11U23 and A15U23 revertants have not yet been probed, their ability to rescue the anomolous sedimentation profile suggests that the All and A15 suppressors act similarly to that of the $U-5$ suppressor.

A potential alternative explanation for the assembly defects observed at low temperature is that the cold-sensitive mutation causes a primarily functional /as opposed to structural) defect. The resulting inhibition of protein synthesis could cause a breakdown in the cooperativity of ribosome assembly, as a result of an imbalance between the availability of ribosomal proteins and rRNA (Dodd et al. 1991). If this were the case, we would expect that both wild-type and mutant ribosomes would be affected, and so both types of $16 \mathrm{~S}$ rRNA should be represented in increased amounts in the aberrant particles.

Primer extension analysis of RNA from these particles (Table 3; C.S. Dammel, unpubl.), however, shows that the increased level of $30 \mathrm{~S}$ and aberrant particles is completely accounted for by the increase in mutant $16 \mathrm{~S}$ rRNA-containing particles, arguing against this possibility. Furthermore, chemical probing shows that the RNA in both 30 S and aberrant particles (but not the RNA in 70S ribosomes) contains structural defects (C.S. Dammel, unpubl.), supporting our interpretation that it is the assembly defect (and its ensuing anomalous structure), rather than the $\mathrm{C} \rightarrow \mathrm{U}$ mutation itself, that prevents the mutant ribosomes from functioning normally.

Thus, our findings suggest that cold sensitivity is caused by an imbalance between the relative stabilities of the precursor and mature helices; weakening of the mature helix appears to be compensated for by a corresponding destabilization of the precursor helix. A simple interpretation would be that the phenotype is caused by a shift in the equilibrium between the two competing helices in the precursor RNA population, and that restoration of the equilibrium suppresses cold sensitivity. In discussing the properties of cold-sensitive mutations in U2 small nuclear RNA (snRNA), Zavanelli and Ares (1991) have suggested that cold sensitivity is relieved at high temperature by increasing the rate of equilibration between two competing helices. Thus, at low temperature, the rate of conversion of helix A into helix B would be rate-limiting, and raising the temperature would increase the rate of interconversion of the two forms. However, the rate of conversion of B into A would also be expected to increase at high temperature, and so an increased rate of equilibration in itself would not account for relief of cold sensitivity at elevated temperatures. But if the rate of conversion of $B$ to a further assembly product, $C$, were much faster than the rate of conversion of $B$ to $A$, the reverse reaction would be decreased owing to depletion of $B$. At high temperature, the effect of rapid recruitment of $B$ to form product $C$ would drive the conversion of $A$ to $B$ forward, thus overcoming the imbalance in the equilibrium caused by the mutation.

Another possible interpretation, and one that we believe is novel in the context of macromolecular assembly, is that destabilization of the mature helix raises the free energy barrier (destabilizes the transition state) for the conversion of precursor to mature helix, thus creating a kinetic trap at this step. Thus, at low temperature, the mutant RNA is kinetically trapped in the precursor conformation; at high temperature, the activation barrier is breached, giving rise to the mature helix, which, although thermodynamically less stable, retains the ability to form a stable protein-RNA complex that drives the complex toward completion of ribosome assembly. This effect of destabilization of an intermediate on its associated transition state is well known to chemical kineticists (Leffler and Grunwald 1963). Whether this concept is applicable to conformational transitions in macromolecules is an intriguing question; if so, it could provide an explanation for the observed cold-sensitive phenotype as well as the effects of the suppressor mutations. 
We note that both interpretations require that the mature helix is an intermediate leading to a more stable product. There is evidence to support the involvement of the mature helix, together with the 920 region in the central domain of $16 \mathrm{~S}$ rRNA, to which it is connected via the pseudoknot interaction, in RNA-protein interactions. Interestingly, these interactions most likely involve ribosomal protein S5 (Stern et al. 1988b). In earlier studies, mutations in this same protein were found to confer strikingly similar cold-sensitive phenotypes (Guthrie et al. 1969a; Nashimoto and Nomura 1970; Nashimoto et al. 1971; Feunteun et al. 1974). The S5 cold sensitive mutations were furthermore associated with assembly defects in the small subunit and gave rise in vivo to particles that resembled RI particles (Nomura and Held 1974). Thus, it may be the case that the coldsensitive C23U mutation, the cold sensitive S5 mutations, and formation of RI particles in vitro at low temperature are all manifestations of closely related events in the assembly pathway of small ribosomal subunits.

Two suppressors located in the upstream 5'-flanking region of the 16S rRNA gene $(U-55$ and $A-114)$ and four suppressors, in the downstream $3^{\prime}$-flanking region of the $16 \mathrm{~S}$ rRNA gene $(\mathrm{A}+8, \mathrm{~A}+13, \mathrm{~A}+23$, and $\mathrm{A}+25)$, lie outside the region containing the two competing helical structures and therefore are not explained in terms of the competing helix model. These double mutants, however, grow poorly or fail to grow on spectinomycin, suggesting that these suppressors may act by creating recessive mutations that inactivate the mutant ribosomes. Nevertheless, there is reason to remain cautious about this interpretation. Although it is clear that growth on spectinomycin requires a critical proportion of functional plasmid-encoded ribosomes in the cell, spectinomycin sensitivity does not necessarily indicate that plasmid-encoded ribosomes are completely inactive or even present at reduced levels. Thus, it remains a possibility that these suppressors may act directly to suppress the cold-sensitive dominance of the C23U mutation.

The C23U mutation results in an increased level of incompletely processed $5^{\prime}$ ends, including some that are noncovalently bound to ribosomal particles (Fig. 7). It is clear, however, that $16 \mathrm{~S}$ rRNA processing itself is not cold sensitive and that incomplete processing is not the cause of cold sensitivity (see results and Fig. 7 ).

We do not yet understand the basis for the dominance of the C23U mutation. One possible explanation is that mutant ribosomes are impaired for initiation. According to this model, incompletely folded, but partially functional, $30 \mathrm{~S}$ precursor particles accumulate at the restrictive temperature, and these particles are effectively able to compete with normal $30 \mathrm{~S}$ subunits for some limiting cellular component such as an initiation factor or some as yet unidentified assembly factor.

Finally, we see no reason why cold-sensitive mutations in macromolecular assemblies involving only protein-protein interactions, such as assembly of the cytoskeleton (Hoyt et al. 1990), could not be explained by similar kinetic trap models, instead of (or in addition to) the often-invoked hydrophobic effect (Nemethy and Scheraga 1962). If our interpretation is correct, it suggests that analysis of cold-sensitive mutations could provide a general approach to genetic dissection of multicomponent molecular assembly pathways. Primary coldsensitive mutations should identify intermediates in the pathway; intragenic suppressor mutations should then provide information about (among other things) alternative conformations, whereas extragenic suppressors should help to identify trans-acting factors involved in complex formation.

\section{Materials and methods}

Bacterial strains and media

Escherichia coli strains $\mathrm{DH} 1\left(\operatorname{Rec}^{-}\right)$, used as host for plasmid constructions and GM2929 $\left(\operatorname{Rec}^{-}, \mathrm{dam}^{-}, \mathrm{Cam}^{\mathrm{r}}\right)$, used to obtain plasmid DNA free of methylation, have been described previously (Triman et al. 1989). All physiological experiments were performed with Luria broth media containing Amp at a concentration of $100 \mathrm{mg} /$ liter $\left(\mathrm{Amp}_{100}\right)$ and spectinomycin at a concentration of $60 \mathrm{mg} /$ liter $\left(\mathrm{Spc}_{60}\right)$, as described previously (Triman et al. 1989).

\section{Plasmids}

Ampicillin-resistant $\left\langle A \mathrm{Amp}^{\mathrm{T}}\right.$ \} plasmid pKK3535 contains the entire $E$. coli $\mathrm{rrnB}$ operon and has been described previously (Brosius et al. 1981). Plasmid pSTL102 is a derivative of plasmid pKK3535 containing the selectable markers U1192 in 16S rRNA (spectinomycin resistance, $\mathrm{Spc}^{\mathrm{r}}$ ) and G2058 in 23S rRNA /erythromycin resistance, Ery ${ }^{\mathrm{r}} \mid$, in addition to ampicillin resistance (Amp ${ }^{\mathrm{r}}$; Triman et al. 1989).

\section{Manipulations of DNA}

Hydroxylamine mutagenesis of plasmid DNA was carried out by use of a modified version of the procedure described by Douthwaite et al. (1985). One hundred microliters of solution A $\left(1 \mathrm{M}\right.$ hydroxylamine in ethylene glycol at $\left.55^{\circ} \mathrm{C}\right)$ was added to 100 $\mu l$ of solution $\mathrm{B}(600 \mathrm{~mm} \mathrm{NaOAc}$ at $\mathrm{pH} 5.4$, containing $1-10 \mu \mathrm{g}$ of plasmid DNA at $55^{\circ} \mathrm{C}$ ) and incubated for $10-15 \mathrm{~min}$ at $55^{\circ} \mathrm{C}$ for isolation of mutants or 5-10 min for isolation of supressor mutations. Reactions were stopped by adding $500 \mu \mathrm{l}$ of ice-cold $6 \mathrm{M} \mathrm{NaI}$ and binding DNA to glass powder for recovery using standard procedures (Geneclean Glassmilk, Biol01, Inc.).

Polynucleotide kinase and restriction enzymes were purchased from New England Biolabs, and T4 DNA ligase was from BRL. Deoxy- and dideoxynucleotides were from Pharmacia, and AMV reverse transcriptase was from Seikagaku America, Inc. Sequenase was purchased from U. S. Biochemical, and radiolabeled nucleotides were from Amersham or New England $\mathrm{Nu}$ clear. Standard procedures for plasmid DNA preparation, agarose gel electrophoresis, DNA fragment purification, restriction fragment mapping, ligations, transformations, and sequencing were performed as described in Triman et al. (1989).

Construction of the plasmid containing U23 without U1192 was accomplished by digesting pU23 and pKK3535 with BamHI and ApaI. The BamHI-ApaI fragment from pU23, which contains U23, was ligated into pKK3535 BamHI-ApaI vector, which lacks U1192. Transformants were selected on Amp plates at $37^{\circ} \mathrm{C}$.

All nucleotide positions discussed in this paper are identified by their positions relative to the first nucleotide of 16S rRNA. 
Plasmid names reflect which nucleotide alterations thay contain. Nucleotide positions upstream from the $5^{\prime}$ mature end of $16 \mathrm{~S}$ rRNA are numbered as negative, where -1 is the first nucleotide $5^{\prime}$ of the start of mature 16S rRNA. Nucleotide positions $3^{\prime}$ of $16 \mathrm{~S}$ rRNA are numbered as positive, where +1 is the first nucleotide $3^{\prime}$ of the $3^{\prime}$ end of 16 S rRNA.

Segregation of second-site mutations from the primary U23 mutation was performed by the subcloning of a Bcll-SacI restriction fragment from pSTL102, into the BclI-SacI vector of revertants pU $-5 \mathrm{U} 23, \mathrm{pU}-55 \mathrm{U} 23, \mathrm{pA}-114 \mathrm{U} 23$, and pA11U23. An analogous exchange between pSTL102 and pA + 8U23 was performed with the BamHI-BstEII fragment and vector. DNA sequence analysis confirmed the presence of the second-site suppressor and the absence of the original $\mathrm{C} 23 \mathrm{U}$ mutation.

\section{Isolation of mutants}

The BamHI-XbaI fragment, containing the 16S rRNA gene and its upstream region, isolated from hydroxylamine-mutagenized pSTL102, was ligated to unmutagenized pSTL102 BamHI-XbaI large fragment and cloned in $\mathrm{DH} 1$. Transformants were selected on $\mathrm{Amp}_{100}$ plates at $26^{\circ} \mathrm{C}$ or $30^{\circ} \mathrm{C}$, and replica plated to $\mathrm{Amp}_{100}$ plates at $26^{\circ} \mathrm{C}$ and $42^{\circ} \mathrm{C}$. These replica plates were then screened for colonies that exhibited reduced growth at one temperature relative to the other.

\section{Isolation of revertants}

DNA was treated with hydroxylamine for either five or ten min, as described above, and used to transform DH1. Transformants were selected and screened on the same $A \mathrm{mp}_{100}$ plate at $26^{\circ} \mathrm{C}$ for suppression of the cold-sensitive phenotype. Revertant candidates are identified as those colonies that appear larger amidst a background of very small cold-sensitive plasmid-containing transformants.

\section{Temperature-shift experiments}

Transformants carrying pSTL102 or pU23 were grown in $\mathrm{Amp}_{100}$ broth, at $42^{\circ} \mathrm{C}$ to $\log$ phase $\left\{\mathrm{A}_{650}=0.3\right\}$, then coldshifted by $1: 5$ dilution into $26^{\circ} \mathrm{C} \mathrm{Amp}_{100}$ broth. The coldshifted cultures were grown to log phase $\left\{A_{650}=0.5\right\}$, with the exception of the U23 culture, which had grown to an $A_{650}$ of only 0.125 in $3 \mathrm{hr}$. These $26^{\circ} \mathrm{C}$ cultures were then shifted by $1: 5$ dilution back to $42^{\circ} \mathrm{C} \mathrm{Amp}{ }_{100}$ broth. The optical density was monitored every 15 or $30 \mathrm{~min}$ for all cultures, until an OD of $>1$ was achieved, or $10 \mathrm{hr}$ had elapsed.

\section{Preparation of ribosomes, rRNA, and total RNA}

To prepare ribosomal particles from $\mathrm{DHl}$ cells containing pSTL102 or pU23, $100-\mathrm{ml} \mathrm{Amp}{ }_{100}$ cultures were grown at $42^{\circ} \mathrm{C}$ to an $A_{650}$ of 0.2 , at which time cultures were shifted to $26^{\circ} \mathrm{C}$ until an $A_{650}$ of 0.55 for pSTL102- or 0.42 for pU23-containing cells was achieved. Chloramphenicol was added to $37^{\circ} \mathrm{C}$ cultures at an $A_{650}$ of 0.5 , at a concentration of $0.1 \mathrm{mg} / \mathrm{ml}$, when the isolation of polysomes was desired (Brow and Noller 1983), followed by incubation with shaking for an additional 2-3 min. Cultures were chilled rapidly by pouring over 50 grams of ice and swirling in a dry ice/ethanol bath. Following freeze-thaw or French press lysis, polysomes and $70 S$ and $30 S$ subunits were isolated by sucrose gradient centrifugation as described by Powers and Noller (1990). rRNA was extracted from the subunits as described by Powers and Noller (1990).

To prepare total rRNA from DH1 containing mutant plasmids, cells were grown in $A \mathrm{mp}_{100}$ broth at $37^{\circ} \mathrm{C}$ and treated as described above, except instead of sucrose gradient fractionation, total ribosomes were pelleted in a Ti50 rotor at 40,000 $\mathrm{rpm}$. for $3.5 \mathrm{hr}$ at $4^{\circ} \mathrm{C}$. rRNA was extracted from the resulting pellet as described above.

Total cellular RNA was prepared from cells containing either pSTL102 or pU23. Amp ${ }_{100}$ cultures $(100 \mathrm{ml})$ were grown at $37^{\circ} \mathrm{C}$ to an $A_{650}$ of 0.6 and placed on ice for $20 \mathrm{~min}$ with occasional swirling. Cells were collected by centrifugation in a GS3 Sorvall rotor at $6000 \mathrm{rpm}$ at $4^{\circ} \mathrm{C}$ for $20 \mathrm{~min}$ and lysed by the freeze-thaw procedure (Powers and Noller 1990). Total RNA was extracted from the resulting supernatant as described by Loening (1969).

\section{Quantitation of plasmid vs. chromosomal 16S rRNA}

Primer extension analysis of plasmid-encoded rRNA, distinguishable by a $\mathrm{C} \rightarrow \mathrm{U}$ mutation at position 1192 in $16 \mathrm{~S}$ rRNA, was performed by the primer extension method of Morgan and co-workers (Sigmund et al. 1988), as modified by Triman et al. (1989). Relative amounts of plasmid-derived versus chromosomally derived 16S rRNA were determined by excising the appropriate bands and counting in a scintillation counter.

\section{Primer extension analysis of $5^{\prime}$-processing of $16 S$ rRNA}

Correct and aberrant $5^{\prime}$ ends of $16 \mathrm{~S}$ rRNA were detected by primer extension using two different primers. The first is complementary to nucleotides 6-22 of mature $16 \mathrm{~S}$ rRNA (internal primer $/ 5^{\prime}$-CCATGATCAAACTCTTC- $\left.3^{\prime}\right)$, and the second is complementary to nucleotides -18 through -1 of precursor 165 rRNA (upstream primer/5'-AAAAGTTTGACGCTCAA$3^{\prime} \mid$. Primer extension was carried out as described by Stern et al. (1988a), with the following modifications. Primers were ${ }^{32} \mathrm{P}-5^{\prime}$ end-labeled using polynucleotide kinase and [ $\left.{ }^{32} \mathrm{P}\right]$ ATP $(>3000$ $\mathrm{Ci} / \mathrm{mmole})$. After annealing the primer (10-fold excess), $3 \mu \mathrm{l}$ of an extension mix, containing $0.5 \mathrm{~mm}$ each dNTPs (dATP, dGTP, dCTP, dTTP|, $2 \times$ extension buffer, and 0.66 units of AMV reverse transcriptase were added and reactions were incubated at $40^{\circ} \mathrm{C}$ for $25 \mathrm{~min}$ and then stopped by ethanol precipitation (Stern et al. 1988a) after the addition of $1 \mu \mathrm{l} \mathrm{of} 10 \mathrm{mg} / \mathrm{ml}$ glycogen carrier. Sequencing reactions were performed as described above except $20 \mu \mathrm{g}$ of total RNA was used and dideoxynucleotides were added at the following concentrations: 0.065 mM ddTTP or ddGTP and $0.037 \mathrm{~mm}$ ddATP or ddCTP. After a 20-min incubation at $40^{\circ} \mathrm{C}, 1 \mu \mathrm{l}$ of $0.5 \mathrm{M}$ EDTA and $1 \mu \mathrm{l}$ of 10 $\mathrm{mg} / \mathrm{ml}$ pancreatic RNase were added and reactions were incubated for an additional $5 \mathrm{~min}$ and stopped by precipitation as described above. The generated cDNA fragments were sized by electrophoresis on denaturing, linear $12 \%$ polyacrylamide gels, in $1 \times \mathrm{TBE}$, at $60 \mathrm{~W}$ for $2.5 \mathrm{hr}$.

\section{Structure probing of mutant ribosomes}

The structure of mutant ribosomes was examined using kethoxal as a probe for the $\mathrm{N} 1$ and/or N2 position of guanine residues (Stern et al. 1988a). Total ribosomal particles were prepared as described above. Kethoxal modification was performed as described by Stern et al. (1988a), except that modification was done at $26^{\circ} \mathrm{C}$ for $10 \mathrm{~min}$. Primer extension was carried out using the 162 primer, specific for the $5^{\prime}$ end of 16 S rRNA, as described by Stern et al. $\{1988 \mathrm{a}\}$.

\section{Acknowledgments}

We thank C. Guthrie, T. Powers, P. Allen, and J. Silverthorne for many valuable discussions, $M$. Ares for discussions concerning mechanisms of cold sensitivity, A.L. Fink, T. Schleich, D. Her- 
schlag, and C. Bernasconi for crucial discussions concerning kinetics and thermodynamics of cold sensitivity, $\mathrm{K}$. Triman for her inspiration and generous help with rRNA genetics, B. Weiser for Figures 1 and 8, and J. Silverthorne, A. Mankin, C. Guthrie, D. Herschlag, and M. Ares for reading the manuscript. This work was supported by National Science Foundation grant DMB-8704076, National Institutes of Health grant GM-17129, and a grant from the Lucille P. Markey charitable Trust.

The publication costs of this article were defrayed in part by payment of page charges. This article must therefore be hereby marked "advertisement" in accordance with 18 USC section 1734 solely to indicate this fact.

\section{References}

Brosius, J., T.J. Dull, D.D. Sleeter, and H.F. Noller. 1981. Gene organization and primary structure of a rRNA operon from Escherichia coli. J. Mol. Biol. 147: 107-127.

Brow, D.A. and H.F. Noller. 1983. Protection of rRNA from kethoxal in polyribosomes: Implication of specific sites in ribosomal function. J. Mol. Biol. 163: 27-46.

Dodd, J., J.M. Kolb, and M. Nomura. 1991. Lack of complete cooperativity of ribosome assembly in vitro and its possible relevance to in vivo ribosome assembly and the regulation of ribosomal gene expression. Biochimie 73: 757-767.

Douthwaite, S., J.P. Prince, and H.F. Noller. 1985. Evidence for functional interaction between domains II and V of $23 \mathrm{~S}$ rRNA from an erythromycin-resistant mutant. Proc. Natl. Acad. Sci. 82: 8330-8334.

Epstein, R.H., A. Bolle, C.M. Steinberg, E. Kellenberger, E. Boy De La Tour, R. Chevalley, R.S. Edgar, M. Susman, G.H. Denhardt, and A. Lielausis. 1963. Physiological studies of conditional lethal mutants of bacteriophage T4D. Cold Spring Harbor Symp. Quant. Biol. 28: 375-394.

Feunteun, J., R. Monier, C. Vola, and R. Rosset. 1974. Ribosomal assembly defective mutants of Escherichia coli. Nucleic Acids Res. 1: 149-169.

Guthrie, C., H. Nashimoto, and M. Nomura. 1969a. Studies on the assembly of ribosomes in vivo. Cold Spring Harbor Symp. Quant. Biol. 34: 69-75.

Guthrie, C., H. Nashimoto, and M. Nomura. 1969b. Structure and function of $E$. coli ribosomes, VIII. Cold-sensitive mutants defective in ribosome assembly. Proc. Natl. Acad. Sci. 63: 384-391.

Hayes, F. and M. Vasseur. 1976. Processing of the 17-S Escherichia coli precursor RNA in the $27-S$ pre-ribosomal particle. Eur. J. Biochem. 61: 433-442.

Hoyt, M.A., T. Stearns, and D. Botstein. 1990. Chromosome instability mutants of Saccharomyces cerevisiae that are defective in microtubule mediated processes. Mol. Cell. Biol. 10: $223-234$.

Leffler, J.E. and E. Grunwald. 1963. Rates and equilibria of organic reactions., pp. 156-161, John Wiley and Sons, Inc., New York.

Loening, U. 1969. The determination of the molecular weight of ribonucleic acid by polyacrylamide gel electrophoresis: The effect of changes in conformation. Biochem. I. 113: 131-138.

Mori, H., C. Dammel, E. Becker, K. Triman, and H.F. Noller. 1990. Single base alterations upstream of the E. coli $16 \mathrm{~S}$ rRNA coding region result in temperature-sensitive 16S rRNA expression. Biochim. Biophys. Acta. 1050: 323-327.

Nashimoto, $H$. and $M$. Nomura. 1970. Structure and function of bacterial ribosomes XI. Dependence of 50 S ribosomal assembly on simultaneous assembly of 30 S subunits. Proc. Natl. Acad. Sci. 67: 1440-1447.
Nashimoto, H., W. Held, E. Kaltschmidt, and M. Nomura. 1971. Structure and function of bacterial ribosomes XII. Accumulation of $21 \mathrm{~S}$ particles by some cold-sensitive mutants of Escherichia coli. I. Mol. Biol. 62: 121-138.

Nemethy, G. and H.A. Scheraga. 1962. The structure of water and hydrophobic bonding in proteins. III. The thermodynamic properties of hydrophobic bonds in proteins. J. Chem. Phys. 36: 3401-3417.

Nomura, M. and W.A. Held. 1974. Reconstitution of ribosomes: Studies of ribosome structure, function and assembly. In $\mathrm{Ri}$ bosomes (ed. M. Nomura, A. Tissieres, and P. Lengyel), pp. 193-223. Cold Spring Harbor Laboratory, Cold Spring Harbor, New York.

Powers, T. and H.F. Noller. 1990. Dominant lethal mutations in a conserved loop in $16 \mathrm{~S}$ rRNA. Proc. Natl. Acad. Sci. 87: 1042-1046.

Sigmund, C.D., M. Ettayebi, A. Borden, and E.A. Morgan. 1988. Antibiotic resistance mutations in rRNA genes of Escherichia coli. Methods Enzymol. 164: 673-690.

Stern, S., D. Moazed, and H.F. Noller. 1988a. Structural analysis of RNA using chemical and enzymatic probing monitored by primer extension. Methods Enzymol. 164: 481-489.

Stern, S., T. Powers, L.M. Changchien, and H.F. Noller. 1988b. Interaction of ribosomal proteins S5, S6, S11, S12, S18, and S21 with 16S rRNA. J. Mol. Biol. 201: 683-695.

Traub, P. and M. Nomura. 1969. Structure and function of $E$. coli ribosomes. VI. Mechanism of assembly of $30 \mathrm{~S}$ ribosomes studied in vitro. I. Mol. Biol. 40: 391.

Triman, K., E. Becker, C. Dammel. J. Katz, H. Mori, S. Douthwaite, C. Yapijakis, S. Yoast, and H.F. Noller. 1989. Isolation of temperature-sensitive mutants of 16S rRNA in Escherichia coli. J. Mol. Biol. 209: 645-653.

Woese, C.R., R. Gutell, R. Gupta, and H.F. Noller. 1983. Detailed analysis of higher-order structure of 16S-like ribosomal ribonucleic acids. Microbiol. Rev. 47: 621-669.

Young, R.A. and I.A. Steitz. 1978. Complementary sequences 1700 nucleotides apart form a ribonuclease III cleavage site in Escherichia coli ribosomal precursor RNA. Proc. Natl. Acad. Sci. 75: 3593-3597.

Zavanelli, M.I. and M. Ares, Jr. 1991. Efficient association of U2 snRNPs with pre-mRNA requires an essential U2 RNA structural element. Genes \& Dev. 5: 2521-2533. 


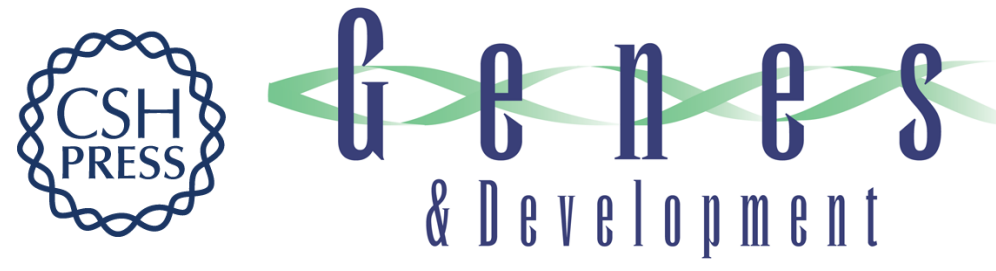

\section{A cold-sensitive mutation in 16S rRNA provides evidence for helical switching in ribosome assembly.}

C S Dammel and H F Noller

Genes Dev. 1993, 7:

Access the most recent version at doi:10.1101/gad.7.4.660

References This article cites 24 articles, 11 of which can be accessed free at:

http://genesdev.cshlp.org/content/7/4/660.full.html\#ref-list-1

License

Email Alerting

Service

Receive free email alerts when new articles cite this article - sign up in the box at the top right corner of the article or click here.

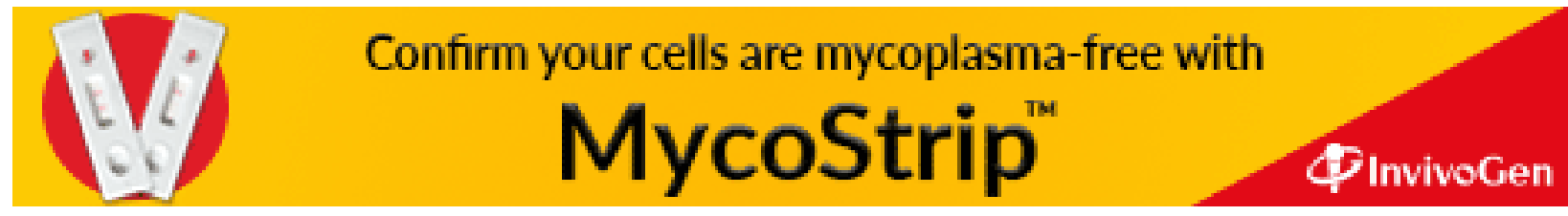

